\title{
METÁFORAS E IMAGENS DOS FORMADORES DE PROFESSORES NA ÁREA DA INFORMÁTICA APLICADA À EDUCAÇÃO*
}

\author{
JOANA PEIXOTO $^{* *}$
}

Tudo, ao mesmo tempo, agora. (Titâs)

\begin{abstract}
RESUMO: O ponto de partida desta pesquisa é a preocupação com a lacuna existente entre a formação dos professores na área da informática educativa (IE) e sua experiência ulterior. A hipótese principal é que existe, entre os formadores dos professores desta área, uma certa representação do modelo de formação que se transferiria automaticamente para a futura prática dos professores. Foi realizada uma enquete com 21 professores da disciplina "Informática e Educação", da Universidade Católica de Goiás, utilizando-se as técnicas de associação livre de palavras, entrevista semi-estruturada e grupo focal. O núcleo figurativo das representaçôes identificadas mostra o computador como um instrumento gerador de transformaçôes educacionais e a informática educativa como o agente promotor das transformaçóes pedagógicas. Esta analogia torna-se uma referência importante que dá forma ao discurso dos formadores por meio de metáforas que constituem o seu imaginário.
\end{abstract}

Palavras-chave: Formação de professores. Informática educativa. Representações sociais.

* Este artigo apresenta o resultado da pesquisa realizada para fins do doutorado em Ciências da Educação na Universidade Paris 8, defendida em março de 2005, orientada por Geneviève Delaunay-Jacquinot e financiada pela CAPES.

** Doutora em Educação e professora no Mestrado em Educação da Universidade Católica de Goiás (UCG).E-mail: joanagyn@yahoo.com.br

Educ. Soc., Campinas, vol. 28, n. 101, p. 1479-1500, set./dez. 2007

Disponível em <http://www.cedes.unicamp.br> 
Metáforas e imagens dos formadores de professores na área da informática...

\author{
TEACHER EDUCATORS' METAPHORS AND IMAGES \\ IN THE FIELD OF COMPUTING APPLIED TO EDUCATION
}

ABSTRACT: The focus of this research is the gap between the formation of educational computing (EC) teachers and their further experience. The main hypothesis is that, among EC teacher formers, there is a certain representation of the educational model and a conception on the beneficial aspects of digital technologies that would be automatically transferred to the future teachers' practice. An investigation was carried out with the 21 teachers of the discipline "Computing and Education" at the Catholic University of Goiás, with the use of techniques of free word association, semi-structured interviews and focus groups. The nucleus of the identified representations shows the computer as a generator of educational changes, and educational computing as the agent of pedagogical changes. This analogy becomes an important reference that shapes formers' discourse by means of metaphors which constitute their imagination.

Key words: Teacher formation. Education and computing. Social representation.

E

sta frase emblemática é cantada pelos jovens brasileiros. E pode ser utilizada também para traduzir um desejo dos formadores de professores da área de informática aplicada à educação (IE): uma abordagem global que deseja considerar tudo ao mesmo tempo.

Os formadores de professores ${ }^{1} \mathrm{em} \mathrm{IE}^{2}$ tentam apreender uma gama variada e complexa de teorias porque não querem limitar sua ação à dimensão técnica ou à dimensão metodológico-pedagógica. Eles reconhecem as implicações econômicas, sociais e políticas da presença marcante das tecnologias, assim como os efeitos da velocidade vertiginosa de suas transformações. Eles se fundamentam num paradigma que valoriza tanto a relação entre comunicação e educação como a crítica das mídias no contexto cultural. Não querem também deixar de considerar as teorias e as propostas sobre formação de professores. O professor é confrontado com a necessidade de compreender quase tudo!

O esforço para considerar todos esses aspectos citados coloca os formadores num quadro de verdadeiras acrobacias teóricas. É possível que essas acrobacias interfiram de maneira significativa na maneira como eles concebem o computador no contexto educativo. O que nós, professores, 
pensamos sobre o computador? Que função nós lhe atribuímos? Estamos lhe atribuindo o poder de reger algo? A máquina implica uma forma diferente de apropriação do saber ou algo inédito? O saber passa pela tecnologia ou por sua lógica?

Esta pesquisa foi, então, direcionada para a identificação e para a análise das crenças e das concepções dos formadores de professores sobre o papel do computador no contexto educativo. Investigou-se a maneira como eles percebem o modelo de formação que colocam em prática e as representações que constroem sobre o computador e sobre seu papel educativo.

A hipótese levantada é que existe, entre os formadores de professores, uma crença em relação a certo modelo de formação em IE, uma forma de perceber a tecnologia digital como portadora de benefícios que se transfeririam automaticamente para a formação e, em seguida, para a prática dos professores. As representações dos formadores sobre o papel pedagógico do computador resistem a integrar aspectos da realidade que eles insistem em denunciar, pois elas mantêm fantasias e idealizações dos formadores relacionadas com o poder transformador que eles atribuem à tecnologia.

Esta hipótese é baseada na idéia de que a representação dos formadores sobre o computador influencia o modelo de formação que eles colocam em prática e, em conseqüência, contribui para a constituição do conjunto de idéias e de práticas simbólicas, assim como do imaginário do professor em formação. Como resultado, a formação dos futuros professores não integra as bases teóricas que lhes permitiriam efetuar a transferência de conhecimentos e, finalmente, desmistificar o computador.

\section{O quadro teórico-metodológico e a coleta de dados}

Há pesquisas sobre a formação e a atuação de professores que fazem a análise das dificuldades de mudanças tanto na concepção como na prática desses profissionais no cotidiano escolar (Gatti, 2003; Nóvoa, 1995; Perrenoud, 1997, 2000 e 2001; Schön, 1992, 1993 e 1996; Tardif et al., 1998; Tardif; Lessard, 1999).

No que diz respeito às tecnologias de informação e comunicação (TIC), há trabalhos que demonstram que a introdução de tecnologias na educação não tem acarretado mudanças significativas nas práticas dos 
Metáforas e imagens dos formadores de professores na área da informática...

professores (Aragón de Nevado et al., 2001; OCDE, 2004; Lagrange; Grugeon, 2003; Pouzard, 1997; Richardot, 2003) e até mesmo que elas podem servir para atualizar os modelos pedagógicos mais arcaicos (Jacquinot-Delaunay, 1985). Há pesquisas que fazem referência também aos obstáculos às mudanças colocados pelos professores (Baron; Bruillard, 2000; Duchâteau, 1996; Gabriel, 1998). Ainda sobre a formação dos professores em TIC, Harrari (2002) trata da lacuna existente entre as políticas educativas e sua aplicação.

As pesquisas indicam que é necessário observar o professor como um ser social e não apenas como uma abstração. Ele está imerso numa vida grupal por meio da qual partilha uma cultura. Seus conhecimentos, valores e atitudes são derivados de suas relações, com base, por sua vez, em representações constituídas num processo que é, ao mesmo tempo, social e intersubjetivo.

Da mesma forma, é necessário levar em conta fatores sociais, políticos, econômicos e culturais de caráter mais amplo que atravessam a vida social ou grupal. A interação entre esses fatores modela as concepções e as práticas que, por sua vez, são delimitadas de maneira estrutural pelo modo como as pessoas se vêem, como elas se descrevem, como elas vêem os outros e a sociedade na qual estão inseridas.

A decisão de adotar o estudo das representações sociais (RS) como categoria analítica desta pesquisa toma como base, então, a possibilidade apresentada por esta teoria de levar em conta a leitura que os sujeitos fazem do mundo e de si mesmos como instrumento para identificar e compreender suas atitudes e ações, já que esta leitura pode exprimir cristalizações, resistências e transformações. Além disso, resultados de pesquisas (Anadón, 2002; Cros, 1997) indicam que o modelo das RS pode contribuir para a compreensão dos fatores que permitem ao professor transformar a sua prática.

É assim que o conceito de RS de Moscovici (1976) foi adotado nesta pesquisa, considerando-se que ele poderia ser útil à investigação que permitiria fazer o levantamento dos aspectos presentes na formação do professor que se referem à subjetividade dos formadores. Trata-se de identificar, por meio da palavra dos formadores, a maneira como eles concebem a formação que colocam em prática.

Os sujeitos desta pesquisa são 21 formadores (de um total de 24) que já ministraram a disciplina "Informática e Educação" nos cursos de 
licenciatura da Universidade Católica de Goiás (UCG). A coleta de dados foi desenvolvida por meio das técnicas da associação livre de palavras, aplicação de entrevistas semi-estruturadas e grupos focais.

Os dados coletados foram trabalhados de forma articulada. As entrevistas foram tomadas como ponto central de análise, mas, para complementar ou aprofundar o trabalho interpretativo, foram levados em consideração os programas e as açôes em IE no Brasil, as tendências atuais na formação de professores e o campo epistemológico gerado no Brasil em torno da IE - o discurso governamental e acadêmico que influencia de forma marcante o pensamento e as açōes dos profissionais que atuam nesta área.

As entrevistas foram estudadas mediante análise temática individual e análise transversal, complementada pelo tratamento feito com a ajuda do software Alceste. A abordagem processual foi adotada neste estudo de RS levando em conta os dois processos fundamentais para a formação das representaçôes: a objetivação e a ancoragem. Enfim, a análise buscou, por meio da distribuição temática, criar uma rede de significaçôes a fim de apreender as representaçôes dos formadores segundo as dimensôes que as compõem, ou seja, o campo estrutural, a atitude e a informação.

A análise do corpus total, obtido a partir da associação de palavras, das entrevistas individuais e dos grupos focais, mostrou a existência de dois grandes blocos, compostos por três classes.

O primeiro bloco - constituído das classes 1 e 3 - refere-se à forma como os formadores entrevistados concebem o computador na educação. Ele apresenta suas expectativas quanto ao papel que o computador deve desempenhar na educação e mostra bem a fratura existente na visão do formador: de um lado, as formulações teóricas; de outro, a prática.

A Classe 1, formada pela população mais jovem e menos experiente, apresenta um discurso ideológico, fundamentado na concepção construtivista e propõe a utilização do computador como uma ferramenta didático-pedagógica. Esse discurso apresenta uma concepção homogênea, com base na literatura da área. É um discurso que indica a representação mais próxima do conceito (ou das teorizaçōes feitas na área). $\mathrm{O}$ computador é apresentado como um recurso educativo. É uma ferramenta de construção de conhecimentos, por meio da qual o professor pode desenvolver e favorecer o processo de aprendizagem dos alunos. É uma tecnologia de aprendizagem. 
Metáforas e imagens dos formadores de professores na área da informática...

\section{Quadro 1}

(Dendograma das classes estáveis)

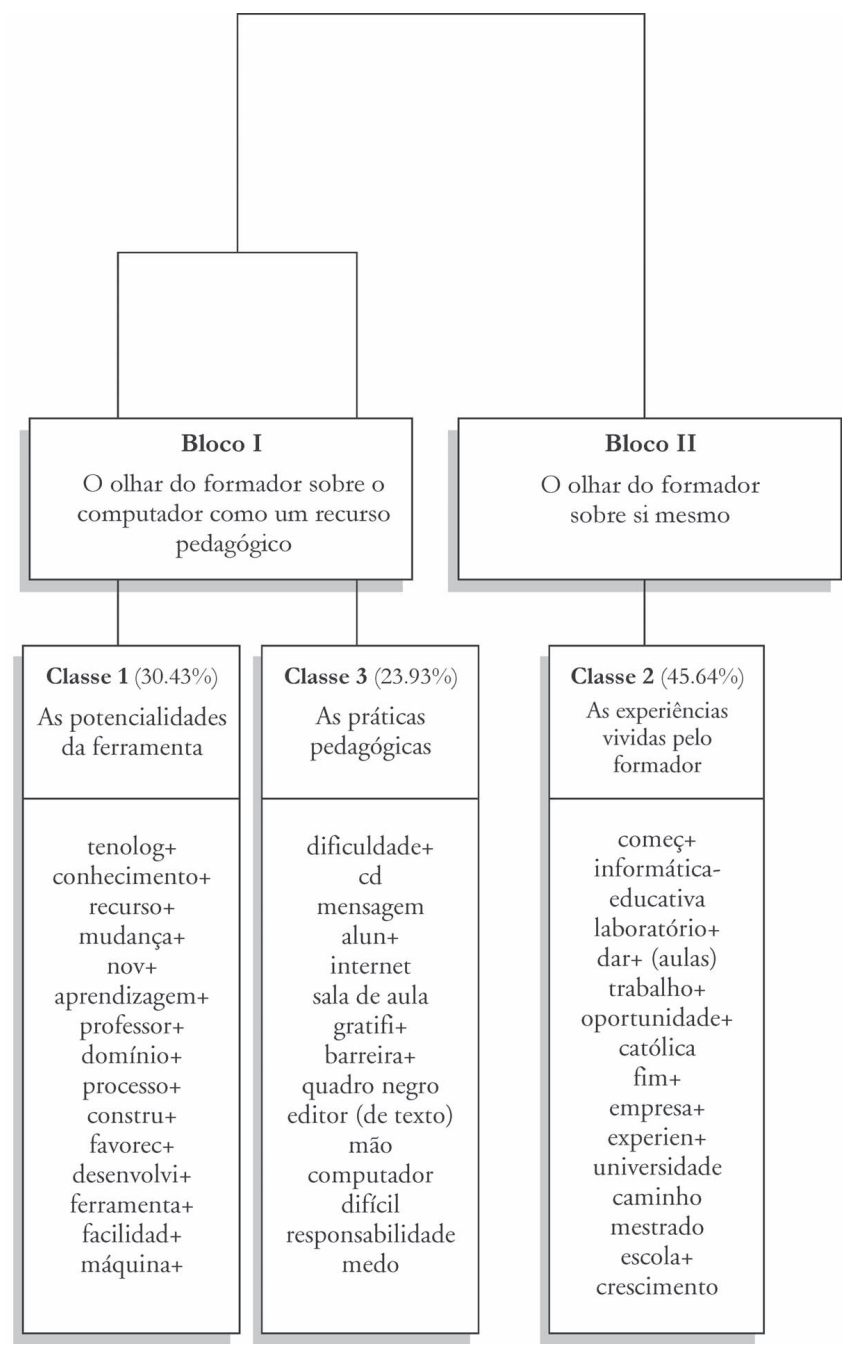


Esse discurso propõe que o computador seja integrado à prática educativa como um meio para facilitar a aprendizagem do aluno. Segundo ele, o professor deve saber "(...) utilizar os recursos tecnológicos, principalmente o computador, de maneira que ele possa ser um recurso que facilite o processo de construção de conhecimento pelos alunos"3 (Paula). $^{4}$

Com um registro principalmente descritivo, no discurso da Classe 3 o formador relata suas experiências de utilização do computador: os recursos oferecidos pela máquina, sua própria reação e a reação de seus alunos diante daquilo que aprendem e das descobertas decorrentes de sua utilização.

No primeiro bloco, que trata o computador como uma ferramenta, encontram-se os formadores que têm menos tempo de trabalho, porém mais experiência de trabalho na área de IE. Os formadores debutantes devem ser os mais ligados às prescriçôes da bibliografia corrente na área, o que pode explicar o discurso mais ideológico e mais próximo das idéias disseminadas na bibliografia adotada nas formaçóes em IE.

O discurso que aparece no Bloco I constrói uma RS marcada por uma tensão entre dois pólos. Esse discurso, referindo-se à leitura que os formadores fazem das potencialidades pedagógicas do computador e de suas práticas com os alunos, indica um núcleo que oscila entre as facilidades e as dificuldades colocadas pela IE.

No início, o computador pode aparecer como um objeto estranho a ser apreendido, como uma caixa preta a ser aberta. Alberto evoca as palavras medo, inacessivel e estranho, quando o computador é proposto como palavra indutora (associação de palavras). Mas, quando se chega a dominá-lo, o computador pode ser um parceiro.

Enquanto para um, o domínio do computador toma forma por meio de sua aplicação com finalidades pedagógicas, para outro, o conhecimento pedagógico precede o técnico, mas há sempre essa distinção entre a dimensão técnica e a pedagógica na formação do professor: "Em primeiro lugar, o professor deve ter conhecimento sobre as possibilidades de uso do computador no processo de ensino-aprendizagem. Depois, ele deve ter o domínio do computador (...)” (Maria).

Portanto, no Bloco I, observamos essa oscilação entre o aspecto técnico e o aspecto pedagógico. 
Metáforas e imagens dos formadores de professores na área da informática...

As dicotomias que emergem do discurso dos formadores não se excluem. De fato, todos os binômios identificados (o difícil e o fácil, o antigo e o novo, o medo e o prazer, a resistência e a motivação) são dicotomizaçôes enraizadas na mesma base que sustenta a fragmentação entre a apropriação técnica e a apropriação pedagógica. Essa dissociação faz parte do esforço empreendido pelos formadores para compreender a fragmentação presente em sua representação da IE.

O núcleo central desta pesquisa - o computador como uma ferramenta pedagógica - foi organizado pelo processo de objetivação, o qual transformou os elementos em figuras ou imagens construídas em torno de pares bipolares. $\mathrm{O}$ computador provoca um conjunto de potentes associações e a representação dos formadores sobre IE pode ser compreendida pela interpretação desses pares. $\mathrm{O}$ discurso do formador engendra imagens acolhedoras ou desprezíveis da IE, tais como: facilidadeldificuldade, diversão/chateação; motivação/resistência, interesse/medo.

O segundo bloco, composto apenas de uma classe, mostra o olhar do formador sobre sua própria experiência em IE. Ele trata de sua formação e de seu percurso de trabalho nas escolas, universidades e centros de formação.

Nesta classe, diferentemente do Bloco I, encontra-se um discurso mais afastado das prescriçōes teóricas, menos normativo, no qual os formadores criticam a formação que receberam e colocam em questão a sua prática:

Eu sei que posso contribuir, eu sei que a minha experiência prática, que foi o meu ponto de partida, contribui muito para o meu trabalho enquanto professora, mas muitas vezes, eu não me sinto segura. (...) Eu me identifico muito com minhas leituras em Informática Educativa e eu acredito no que eu faço em sala de aula, mas eu me sinto ainda balbuciante num terreno de novidades. (Vânia)

E também revelam o prazer de trabalhar nesta área:

Então, eu percebi que, o que diversas Semanas Pedagógicas, cursos de formação e de preparação não conseguiam atingir, (...) uma passagem por este tipo de formação que nós propomos, chegava a mudar de maneira significativa a prática do professor (...). Era quase um milagre que a gente atribuía ao contato do professor com este tipo de curso que a gente propunha. Era quase um milagre, claro que não se trata de um milagre, mas o curso chegava a fazer, a operar esta mudança no professor. (Alberto) 
Trata-se de um discurso mais heterogêneo que, provavelmente, reflete a sensibilidade dos sujeitos à ambigüidade das situações vividas.

Os sujeitos típicos do Bloco II têm de 2 a 10 anos de experiência em IE e idade média entre 36 e 49 anos. Eles não estão nem no início, nem no fim de sua carreira profissional ou de seu trabalho em IE. Provavelmente, encontram-se ainda em uma etapa em que pretendem e devem conquistar novos espaços de trabalho, estando portanto abertos às inovações (Huberman apud Nóvoa, 1995). Falam longamente a respeito de sua formação, de sua inserção na área e das características de seu espaço de trabalho. Eles fazem a crítica da formação que receberam, afirmando a necessidade de uma formação mais prática e destacam que o aperfeiçoamento de sua prática se deu com base na experiência em IE.

$\mathrm{O}$ testemunho dos formadores menos experientes indica que ainda somos muito marcados pelos modelos tradicionais de formação, com base em cursos nos quais nós aprendemos primeiro as teorias e em seguida as práticas, o que torna mais difícil o estabelecimento de ressignificações e inovações a favor da construção de um novo processo de ensino. São cursos que ainda não romperam com a alternância que justapõe estágios sem conteúdos e unidades de formação sem acesso à prática (Perrenoud apud Tardif et al., 1998).

No discurso presente na Classe 2, uma boa parte dos formadores testemunha uma busca que os levou a esta via profissional: "O que eu estava fazendo não me satisfazia mais e eu acho que eu não poderia desenvolver nada para o qual eu já estava preparada (...). Então, seria necessário procurar alguma coisa prazerosa no trabalho (...) e é assim que eu comecei a fazer uso do computador (...)" (Gabriela).

Eles revelam também o prazer em descobrir uma ferramenta cognitiva potente. Essa descoberta coloca-os na condição de questionar e de mudar a sua prática; portanto, falam de sua grande satisfação em ver que alguns colegas conseguem transformá-la. Eles demonstram também seu contentamento em ver seus alunos colocarem em prática, ainda no decorrer de sua formação, o que ali aprenderam.

Eu estou muito contente com o resultado de meu trabalho. Eu tenho o retorno de alguns alunos que antes não utilizavam as tecnologias porque desconheciam as possibilidades de sua utilização e que, após as discussões e as leituras em sala de aula, começaram a utilizá-las. É gratificante perceber que meu trabalho está disseminado, que os professores chegam à escola 
Metáforas e imagens dos formadores de professores na área da informática...

e levam os alunos para o laboratório. É gratificante perceber que eles, de certa forma, perdem o medo e a resistência de utilizar o computador e as tecnologias. (Cláudia)

Por fim, eles querem prolongar essa descoberta prazerosa partilhando-a com seus colegas e alunos. No entanto, apesar dos resultados positivos anunciados, os relatos decepcionantes ainda são numerosos. Eles denunciam a discriminação, a desconfiança e a crítica dos colegas professores. Falam da resistência de seus alunos e também da recusa dos professores formados em colocarem em prática o que eles mesmos consideraram positivo em sua formação.

As idéias que adotam como fundamento de suas ações não lhes ajudam a equacionar as ambigüidades diante das quais eles se encontram. Dada a complexidade e a amplitude das questôes implicadas na integração das TIC na educação, os textos estudados abordam distintamente: o caráter político das contradições existentes entre os programas oficiais e as condições sociais; uma leitura filosófica dos objetos técnicos como produções culturais; o aspecto comunicacional das TIC ou as aplicações didático-pedagógicas das tecnologias. Cabe aos formadores articular essas diversas abordagens a fim de superar a mera constatação de suas dificuldades. Eles se angustiam diante deste quadro, mas desenvolvem, também, sistemas de explicação visando compreender e superar as lacunas entre teoria e prática.

Eu penso então que houve uma mudança, não se tratava de encontrar uma resposta, houve uma mudança de percepção, na minha maneira de ver as coisas (...). Foi o curso que permitiu isto. Então, algumas vezes, você vai fazer um curso pensando que vai encontrar uma resposta. Mas ele não mostra uma resposta, ele te mostra um caminho a ser percorrido (...). Eu penso que eu encontrei mais do que buscava. Eu encontrei mais, porque eu encontrei um campo de busca ainda maior. Eu encontrei um poço sem fundo. (Mírian)

É assim que nós os observamos apresentar que razões que buscam explicar: que o professor não coloca em prática a formação que recebeu, que a formação não foi adequada, que a introdução de tecnologias e a conseqüente transformação das relações pedagógicas são apenas uma questão de tempo, que o computador motiva o aluno a aprender de maneira autônoma, o que deveria engendrar transformações nos professores. 
Em relação ao papel do computador na formação do professor, foram encontradas duas visões. Na primeira, o computador é visto como desencadeador (provocador) "natural" de uma educação mais rica; na segunda, como uma ferramenta privilegiada para transformar as práticas pedagógicas, que se antecipa à transformação inevitável da escola e reivindica para si mesma a possibilidade de escolher uma direção para essas transformações.

Eu penso que não é SOMENTE a presença das tecnologias que exige estas mudanças (...). A gente aprendia uma coisa na Universidade e aquilo nos acompanhava até o fim da vida, quase da mesma maneira. E hoje não, a sociedade exige que nós sejamos mais dinâmicos, mais criativos, mais competentes sobre o que fazemos, (...). Eu penso que a tecnologia tem este papel, ajudando e dando o sinal de alerta: é preciso fazer mudanças! (Vânia)

Um mesmo formador pode transitar entre as duas opções acima, confirmando ou negando o papel do computador como catalisador de mudanças nas práticas pedagógicas. Um exemplo aparece no decorrer de um grupo focal:

Regina: "Eu também, entendo desta maneira. Ele vai provocar, ele vai fazer o professor, com o computador, levar o aluno a trabalhar de uma forma diferenciada, torná-lo um parceiro da mudança. Porque ele é moderno, ele é atual, ele pode enriquecer, ele vai mudar, sim, esta metodologia, ele vai provocar esta transformação".

Zélia: "Eu vejo esta afirmação da seguinte forma. Eu tenho tendência a fazer esta observação porque nós vemos, muitas vezes, que nós atribuímos ao computador as mudanças na educação. E esta mudança não acontece, na minha opinião, a partir da utilização de uma tecnologia, como o computador. Através de leituras e de discussões, nós vemos ser atribuído ao computador este poder que nenhum equipamento tem em si mesmo. Então, tem as relaçôes sociais, tem a vida da escola, o currículo vivo da escola, que vai fazer, que a metodologia adotada pelo professor (...) possa ser alterada. Mas não é a utilização...”.

Regina: “... da máquina”

Zélia: "da máquina"

Regina: "Não, eu estou de acordo com você, a máquina sozinha não, mas ela pode ser parceira do professor". 
Metáforas e imagens dos formadores de professores na área da informática...

(...)

Virgínia: “(...) Eu estou de acordo que a utilização do computador torna possivel uma mudança. Mas ele torna possível, exatamente na medida onde ele possa, realmente, ser utilizado de forma diferente da maneira tradicional, ou seja, utilizar o computador sem objetivo, sem planejamento, sem uma perspectiva para que ele possa contribuir para uma metodologia melhor, mais adequada ao estudo que está sendo feito. Então, eu não compreendi da mesma maneira que você. Eu compreendi como um leque de possibilidades. Ele pode levar à mudança na prática pedagógica ou não (...)”. (grifos da autora)

No processo de apropriação de um objeto ou de uma idéia ainda imprecisa, o sujeito pode se encontrar na impossibilidade de nomeá-los ou de conceituá-los. Nesse caso, as metáforas se apresentam como uma maneira prática de categorizar o objeto desconhecido e de integrá-lo aos conhecimentos anteriores.

\section{Imagens e metáforas no discurso dos formadores em IE}

A representação que os formadores de professores fazem de IE nasce de um modelo de formação em IE que pretende transformar as práticas educativas e instaura um modelo de educação centrado na aprendizagem autônoma do aluno. Essa representação é tributária também de uma prática que o formador pretende renovar. A adoção das práticas novas pode ser impulsionada pela vontade dos professores de IE, mas também é necessário que sua iniciativa seja apoiada, favorecida e mesmo prescrita pela estrutura escolar na qual esses profissionais exercerão sua função.

Esta pesquisa indica que é no confronto entre as demandas de sua formação, o compromisso com uma mudança educacional, as prescrições teóricas e as exigências de enquadramento nos programas oficiais de IE que o formador constrói suas representações sobre o papel educativo do educador.

Em virtude da descrição dos resultados que considera as dimensões das RS, foi reconstruído o núcleo figurativo, englobando os conhecimentos e as imagens produzidas com base no discurso dos formadores, subdividido em três classes ou temas: as concepções do computador como ferramenta didático-pedagógica, a utilização do computador no contexto educativo e as experiências do formador na área de IE. 
O núcleo figurativo da representação dos formadores apresenta o computador como um instrumento capaz de produzir transformações educacionais, ou seja, a Informática Educativa é vista como o elemento catalisador das transformaçōes pedagógicas. Essa analogia emerge como uma figura modelo, desempenha um papel fundamental e modela o discurso dos formadores.

As estruturas definidas pelas representações não se constituem em dados objetivos; elas são historicamente produzidas pelas práticas sociais, políticas e discursivas que constroem suas figuras. Assim, as práticas discursivas são caracterizadas como produtoras de divisōes, de ordenação e de apropriação do real.

As RS, definidas por Moscovici como um conjunto de conceitos, foram aqui examinadas como uma rede de metáforas geradas na interação social, como um sistema conceitual estruturado e estruturante da realidade. Em um artigo que trata das metáforas como figura argumentativa central na coordenação discursiva, Mazzoti (2003, p. 101) afirma que "As metáforas, por serem analogias condensadas, podem ser examinadas de maneira a expor o esquema analógico utilizado pelos entrevistados, viabilizando uma interpretação mais controlada de seus argumentos".

As metáforas são configuradas, de fato, como um mecanismo construtivo do pensamento, orientado por uma lógica de imputação de sentido aos objetos e aos eventos. Entre esses mecanismos de apropriação da realidade, foram encontradas algumas metáforas que tentam definir ou construir a representação de IE como marca do formador por meio de expressōes como: "terreno de novidades", "leque de possibilidades", "espelho", "alerta" (em relação às mudanças), "um poço sem fundo".

A atitude do formador em relação ao computador aparece como a afirmação de seus valores pedagógicos. Ele pode ser um negócio difícil ou pode representar riscos quando não é integrado a um projeto construtivista. No entanto, o formador o mantém como um desafio a ser superado, nunca como um projeto a ser abandonado. Aliás, é justamente em razão de sua ligação com o projeto de IE que o formador se encontra nesse quadro de grandes desafios práticos e acrobacias teóricas.

Essas acrobacias podem caracterizar o nível de informação dos formadores. Os diferentes conhecimentos, nos quais a imagem do computador como catalisador das transformaçōes educacionais está ancorada, não lhes oferecem elementos suficientes para fazer a síntese entre o 
Metáforas e imagens dos formadores de professores na área da informática...

paradigma construtivista, a crítica aos programas oficiais e a estrutura educacional.

Além disso, observa-se que as imagens que os formadores constroem da IE estão relacionadas com algumas matrizes do pensamento moderno sobre a técnica (Heidegger, 2002; McLuhan, 1968). São imagens que carregam a idéia da técnica como um objeto cultural e como um meio a ser controlado pelo homem.

De maneira geral, os formadores proclamam a necessidade de controlar a máquina, de saber operá-la a fim de poder aplicá-la a finalidades pedagógicas. As idéias referentes à técnica como um meio de controle da natureza são colocadas em questão por Stiegler (1994, 1996), para quem a técnica, ao se apropriar da natureza, se apropria do homem, porque ele faz parte dessa natureza. Considerada nesse sentido, a técnica é constitutiva do homem e da vida social. E, sendo constitutiva do homem e do sentido social, não é apenas um meio ou instrumento.

Essas reflexões são propostas como algo a ser incorporado à bagagem do formador, como uma via de emancipação desta espécie de impasse no qual ele se encontra no que diz respeito à relação entre o computador e um projeto pedagógico que seja inovador. ${ }^{5}$

Até aqui essa idéia se constitui apenas em uma pista que pode contribuir para que o formador possa superar essa maneira mistificada de ver a IE. Se nós levarmos em conta a experiência atual dos formadores, poderemos interpretar que eles se encontram na busca por emancipação e construção de uma identidade individual e coletiva autônoma. Nós podemos considerar sua experiência como um espaço no qual possam se autorizar a reconhecer não só as possibilidades, mas também as impossibilidades de integração da informática à educação. Os formadores poderão, então, reconhecer a IE como uma experiência que levanta mais questôes do que propóe respostas: um poço sem fundo.

Retomemos o processo de formação dos formadores em IE. Constatou-se, por meio do discurso dos formadores, a importância de sua descoberta das possibilidades que o computador oferece à educação. Considera-se que essa relação com o computador, oriunda principalmente de sua formação em IE, é um momento fundador de um espírito e de um desejo que vão animá-los no decorrer de sua experiência nesta área.

$\mathrm{O}$ computador, revestido do tipo de formação que o introduziu nesta área, permitiu ao formador a mediação entre o novo e o antigo, 
entre o familiar e o estranho, entre um modelo de educação conhecido/praticado e o desejo de uma nova educação.

Esse tipo de formação atribui ao formador a tarefa de controlar a máquina, assim como lhe investe da tarefa de conhecer as teorias que possam explicar, traduzir e fundamentar suas aplicações pedagógicas. Ele parte do estranho em direção à ancoragem desse novo objeto em um mundo que deverá se tornar, novamente, familiar. Trata-se de um terreno de novidades que devem ser controladas. Essa tarefa acarreta provaçôes e descobertas. Neste nível, o formador representa o computador em sua ambigüidade. A integração do computador à educação é alguma coisa gostosa, uma diversão, uma satisfação porque motiva, provoca interesse, é um facilitador do processo de aprendizagem. Mas ela é também uma chateação, uma dificuldade gigantesca, um negócio difícil que gera o medo e a resistência.

De qualquer maneira, é necessário controlar a inovação, integrando-a a um projeto. A literatura estudada e os programas oficiais indicam ao formador um projeto que ele critica, mas que também tenta assimilar a fim de resolver as demandas colocadas pela prática. No entanto, apesar dos riscos de uma má utilização das tecnologias e da distância entre os programas governamentais e as necessidades de uma escola pública de qualidade, o formador continua convencido e motivado a seguir o caminho aberto pela IE.

O computador, nas perspectivas abertas pelo contexto da formação do formador, o incitou a se deslocar do lugar em que estava, levando-o a fazer uma espécie de viagem. Essa viagem não é a mesma da escola que o formador conheceu - aquela em que o caminho é estabelecido a priori, traçado por meio de currículos lineares e que propõem conteúdos cumulativos em razão de um objetivo final predeterminado. Entrar no mundo da IE significa, para o formador, se aventurar, perder-se num espaço de divagação, de busca de respostas e ir ao encontro de novas questóes.

A IE é vivida pelo formador como um lugar de estudo, de educação. Ele se sente angustiado porque se sente abalado em suas certezas anteriores. Teve acesso a um espaço que pode ser explorado, no qual ele próprio traça seu caminho. Uma viagem animada pela fascinação de novas descobertas. Aceitou o desafio e colocou em questão os esquemas preestabelecidos, mas não pode dispensar todo e qualquer ponto 
Metáforas e imagens dos formadores de professores na área da informática...

de referência. Neste nível, ele pode se ligar a um projeto de IE, mas isso implica submissão a prescriçôes e a um modelo e, de certa maneira, a uma mistificação dos poderes pedagógicos do computador, que é, então, representado como uma ferramenta que pode acarretar ou ser portadora de mudanças.

Após ser assimilada, a máquina não é mais vista de uma forma dicotômica, mas é percebida sob diversas facetas: como um alerta às necessidades de mudança, como um espelho no qual os professores vêem e avaliam a sua prática, como um recurso pedagógico a mais que o professor utiliza para se manter atualizado com as inovações. Mas o computador é representado principalmente como um parceiro do professor, como uma rica ferramenta que motiva os alunos e facilita sua aprendizagem.

A aceitação e a assimilação deste objeto estranho permitem ao formador seguir a sua viagem e, talvez, se aventurar um pouco mais. Ele pode reconhecer a IE como um mundo mais de perguntas do que de respostas. E se autoriza a lidar com algo que não seja mais inteiramente controlável, um campo de novidades. Ao reconhecer e aceitar esse mundo de mudanças constantes, o formador representa a IE como um leque de possibilidades.

Ao ser convenientemente representada e assimilada, a IE se despe de sua inquietante bizarrice. O computador é um espelho, o motor de nossas ações. Desse modo, a mistificação persiste. Por intermédio da reflexão sobre sua experiência, o formador busca desenvolver os fundamentos de sua ação. Ele não pode continuar nos limites da teoria e isso tem origem numa crise, aquela que representa sua insatisfação inicial e que o fez buscar a IE como um outro espaço de trabalho.

Um relato de crise constrói o presente como um momento crítico no duplo sentido da palavra. Um momento decisivo e um momento de crítica: um momento em que o sujeito recupera criticamente sua própria história e se apropria dela a fim de saber onde ele se encontra e qual o novo passo a dar em busca da emancipação definitiva. Neste sentido, os relatos de crise são um registro apocalíptico.

Pode-se observar que os formadores em IE atribuem ao computador este poder emancipador que eles querem exercer e que eles gostariam de repasssar aos professores em formação, assim como aos seus futuros alunos. Isso pode representar a prefiguração do momento utópico de um salto inovador em direção à invenção de novas possibilidades. 
Por meio dessa representação, o formador responde à necessidade de poder tornar inteligível sua realidade, tomando decisōes, fazendo escolhas, assumindo a qualidade de autor de um discurso. A experiência do formador não pode ser representada e transmitida a não ser por intermédio de uma imagem aproximativa, como um poço sem fundo. Neste sentido, a IE é mais uma utopia que um mito, traduzindo a busca de superação da dicotomia entre a formação e a prática.

Dessa maneira, volta-se ao ponto de partida desta pesquisa: a distância existente entre o que os professores aprendem no decorrer de sua formação em IE e o que eles colocam em prática. Os formadores que integram o acordo PROINFO-OEA (Valente, 2003) reconhecem essa distância e fazem algumas proposiçōes. Põe-se em destaque, aqui, uma dessas proposiçōes que tem relação com um dos elementos que figuram no núcleo central da representação construída pelos formadores: a transformação na prática do professor. Essa transformação só pode ocorrer se o seu ator estiver convencido de sua necessidade e se ele estiver disposto a se transformar, porque isso implica não só um esforço pessoal, mas também uma ação coletiva que faça frente aos obstáculos impostos, principalmente aos procedimentos escolares cristalizados em estruturas tradicionais e conservadoras. Portanto, a transformação não pode figurar como um objetivo proposto, mas como "(...) uma possibilidade a partir da circunstância criada pelo ambiente reflexivo" (Almeida apud Valente, 2003, p. 44).

Choplin (2002) nos apresenta uma reflexão similar no que diz respeito a projetos educativos que propõem a mudança de paradigma como objetivo. Segundo ele, visar ao paradigma construtivista parece ser o melhor meio de evitar a expansão do movimento inovador, porque a vontade de mudança, determinada por uma meta, desconhece a maneira como a inovação se constitui segundo metas plurais, freqüentemente modificadas no decorrer do processo de mudança.

Se não colocarmos a transformação das práticas pedagógicas como um objetivo dos programas de formação, poderemos, em princípio, delimitar a experiência formadora em seu quadro de ação real. Os estudos sobre as condições socioeconômicas, sobre o contexto educacional e sobre a realidade escolar são fundamentais, mas eles, evidentemente, não tornam esse contexto pronto para acolher e sustentar as práticas inovadoras. Ao contrário, a sistematização do discurso inovador pode provocar a organização de uma reação das forças que se opõem às mudanças. Pode-se 
Metáforas e imagens dos formadores de professores na área da informática...

supor que o deslocamento da transformação da função de objetivo libera o formador da carga que decorre das ambigüidades que o obrigam a ocultar algumas de suas dificuldades ou a virar as costas a uma parte da realidade. Como foi visto, a confrontação entre a formação recebida e as práticas em vigor, de um lado, e as proposiçôes construtivistas em IE, de outro, colocam o formador num quadro de contradição.

Se a ênfase da formação é colocada na experiência da formação como uma viagem (Larrosa et al., 1995), a transformaçâo pode ser vista como resultado, é claro, mas poderia ser, sobretudo, integrada ao processo de formação. A viagem da formação é dirigida principalmente para o ser em formação e o computador poderia ser visto como um objeto técnico que pode integrar este processo (como um espelho ou um parceiro). A transformação das práticas não poderia então ser apreciada ao final de um curso, mas por meio de aproximaçóes sucessivas, num processo de equilíbrio que só poderia ser produzido no contexto de uma formação contínua.

Ao adotarmos a concepção de formação como uma relação linear entre projeto e resultados, podemos lhe atribuir finalidades utópicas. É possível colocá-la numa linha temporal unidirecional que leve à transformação das práticas pedagógicas. Mas se tomamos a formação como uma viagem, na qual todos os atores assumem o poder de tornar real o possível, poderemos também nos emancipar da relação com a máquina como um meio ou como um desvelamento.

A atenção deve então se dirigir para a produção de subjetividade implicada nos dispositivos técnicos. É possível que, quando esquecermos o desejo de mudança, quando aceitarmos as inquietudes de uma prática instável, encontremos estratégias de formação que possam mantê-la como um campo de novidades. Mas, certamente também, quando tivermos a coragem de admitir o computador como um objeto técnico que constrói uma subjetividade, nos daremos os meios de reconstruir o real, mudando, assim, a nossa prática.

Recebido em setembro de 2006 e aprovado em novembro de 2006.

\section{Notas}

1. No contexto desta pesquisa, o termo "formador" foi utilizado para designar os formadores de professores. 
2. A sigla IE será utilizada para indicar "informática e educação", "informática educativa” ou "informática aplicada à educação". A maneira de nomear um objeto de representação não é anódina. Dizer o nome de alguma coisa não é simplesmente nomeá-la, mas, também, convidá-la a corresponder à maneira como ela foi nomeada. A comunicação é, portanto, um processo construtivo de sentido. No Brasil, tais expressões são adotadas para designar a utilização do computador como ferramenta didático-pedagógica. A definição de computador como máquina encontra eco nas produçóes escritas no domínio da IE. No material analisado nesta pesquisa, encontram-se referências a "sala dos computadores", "monitor do computador", assim como à "utilização pedagógica do computador" ou "utilização do computador na escola" ou "na educação". A informática é tomada como: o conjunto de técnicas de tratamento automático de informação, mas é principalmente utilizada como sinônimo de computador: "sala de informática", "introdução à informática na educação", "utilização da informática com os alunos". A este propósito, há um artigo de Pochon (2003) que propóe uma discussão interessante sobre o uso pedagógico do computador por meio de siglas.

3. Os testemunhos dos sujeitos da pesquisa aparecem entre aspas no texto e em corpo menor, nos destaques.

4. Os nomes dos sujeitos da pesquisa foram alterados, a fim de preservar sua identidade.

5. Segundo Cros (1997), a inovação pedagógica é um processo que tem por intenção uma ação de mudança, e por meio da introdução de um elemento ou de um sistema em um contexto estruturado. Então, a inovação se define em referência a uma situação ou contexto. Ou seja, o que pode definir uma inovação é sua aplicação social. No caso de uma inovação tecnológica, adota-se a compreensão de que não é o objeto técnico em si mesmo que provoca as mudanças, mas a maneira como ele penetra no tecido social.

\section{Referências bibliográficas}

ANADON, M. Représentations et éducation: quelques réflexions théorico-méthodologiques. L'Année de la Recherche en Sciences de l'Education, Maine-et-Loire, p. 227-244, 2002.

ARAGON de NEVADO, R. et al. Um recorte da arte: o que está sendo produzido? o que está faltando segundo nosso subparadigma? Trabalho apresentado no Simpósio Brasileiro de Informática na Educação, 2001, Vitória (ES). Disponível em: <http://www.nied.unicamp.br/oea>. Acesso em: 14 nov. 2004.

BARON, G-L; BRUILLARD, E. Technologies de l'information et de la communication dans l'éducation: quelles compétences pour les enseignants? Education \& Formations, Paris, n. 56, p. 153-159, 2000.

CHOPLIN, H. Entre innovation et formation ouverte, les "nouveaux dispositifs de formation". Education Permanente, Arcueil, v. 3, n. 152, p. 7-15, 2002.

Educ. Soc., Campinas, vol. 28, n. 101, p. 1479-1500, set./dez. 2007

Disponível em <http://www.cedes.unicamp.br> 
Metáforas e imagens dos formadores de professores na área da informática...

CROS, F. L'innovation en éducation et formation. Revue Française de Pédagogie, Paris, n. 118, p. 127-156, 1997.

DUCHÂTEAU, C. Pourquoi l'école ne peut intégrer les nouvelles technologies? Apresentado no Symposium L'école de demain à l'heure des technologies de l'information et de la communication, sept. 1996, Montréal.

GABRIEL, P. Enseignement et informatique pour tous: où en sommesnous? Revue Française de Pédagogie, Paris, n. 124, p. 99-108, 1998.

GATTI, B.A. Formação continuada de professores: a questão psicossocial. Cadernos de Pesquisa, São Paulo, n. 119, p. 191-204, 2003.

HARRARI, M. Comparer la prise en compte des technologies de l'information et de la communication dans les systèmes éducatifs de différents pays? In: Baron, G-L.; Bruillard, E. Les technologies en éducation, perspectives de recherche et questions vives. Paris; Caen: INRP, PNER; BasseNormandie: IUFM, 2002. p. 61-71.

HEIDEGGER, M. A questão da técnica. In: Heidegger, M. Ensaios e conferências. Petrópolis: Vozes, 2002. p. 11-38

JACQUINOT-DELAUNAY, G. L'école devant les écrans. Paris: ESF, 1985.

LAGRANGE, J-B.; GRUGEON, B. Vers une prise en compte de la complexité de l'usage des TIC dans l'enseignement : une métha-analyse des publications d'innovation et de recherche en mathématiques. Revue Française de Pédagogie, Paris, n. 143, p. 101-111, 2003.

LARROSA, J. et al. Déjame que te cuente: ensayos sobre narrativa y educación. Barcelona: Laertes, 1995.

MAZZOTTI, T.B. Metáfora: figura argumentativa central na coordenação discursiva das representações sociais. In: CAMPOS, P.H.F.; LouREIRO, M.C.S. Representaçôes sociais e práticas educativas. Goiânia: UCG, 2003. p. 89-102.

MOSCOVICI, S. La psychanalyse, son image et son public. 2. ed. Paris: PUF, 1976.

McLUHAN, M. Pour comprendre les médias: les prolongements technologiques de l'homme. Trad. de Jean Paré. Paris: Seuil, 1968.

NÓVOA, A. (Org.). Profissão professor. Porto: Porto, 1995. 
ORGANISATION FOR ECONOMIC CO-OPERATION AND DEVELOPMENT (OCDE). L'OCDE constate que l'utilisation des TIC est "décevante" dans les établissements d'enseignement secondaire du second degré, 2004. Disponível em: <http://www.oecd.org/document/18/ 0,2340,fr_2649_201185_26304850_1_1_1_1,00.html>. Acesso em: 30 mar. 2004.

PERRENOUD, P. Construire des compétences dès l'école. Paris: PUF, 1997.

PERRENOUD, P. Pédagogie différenciée: des intentions à l'action. 2. ed. Paris: ESF, 2000.

PERRENOUD, P. et al. (Ed.). Former des enseignants professionnels: quelles stratégies? quelles compétences? 3. ed. Bruxelles: De Boeck Université, 2001.

POCHON, L.-O. Quelques repères historiques et culturels concernant les NTIC et leur usage dans l'éducation et la formation. Cahiers de Psychologie, Neuchâtel, n. 39, dec. 2003. Disponível em: <http:// www.unime.ch/psy> Acesso em: $12 \mathrm{dez} .2004$.

POUZARD, G. Préface. In: SAndholtz, J. H. et al. La classe branchée: enseigner à l'ère des technologies. Paris: CNDP, 1997. p. xi-xiii.

RICHARDOT, S. Représentations sociales et intégration des médias à l'école. In: Bonardi, C. et al. Psychologie sociale appliquée: economie, médias et nouvelles technologies. Paris: In press, 2003. p. 253-274.

SCHÖN, D. Formar professores como profissionais reflexivos. In: NóvoA, A. (Org.). Os professores e a sua formação. Lisboa: D. Quixote, 1992. p. 77-92.

SCHÖN, D. Le praticien réflexif: à la recherche du savoir caché dans l'agir professionnel. Montréal: Logiques, 1993.

SCHÖN, D. (Dir.). Le tournant réflexif: pratiques éducatives et études de cas. Trad. de Jacques Heynemand e Dolorès Gagnon. Montréal: Logiques, 1996.

STIEGLER, B. La technique et le temps: la faute d'Epiméthée. Paris: Galilée, 1994. v. 1. 
Metáforas e imagens dos formadores de professores na área da informática...

STIEGLER, B. La technique et le temps: la désorientation. Paris: Galilée, 1996. v. 2 .

TARDIF, M. et al. Formation des mâtres et contextes sociaux. Paris: PUF, 1998.

TARDIF, M.; LESSARD, C. Le travail enseignant au quotidien: expérience, interactions humaines et dilemmes professionnels. Bruxelles: De Boeck Université, 1999.

VALENTE, J.A. (Org.). Formação de educadores para utilização da informática na escola. Campinas: NIED; UNICAMP; OEA, 2003. 